\section{Review of ocean temperature, salinity and oxygen changes in the Pacific and subtropical southern hemisphere}

To cite this article: Lynne D Talley 2009 IOP Conf. Ser.: Earth Environ. Sci. 6032009

View the article online for updates and enhancements.

- Ultra-low noise HEMTs for high-
$\frac{\text { impedance and low- frequency }}{\text { preamplifiers: realization and }}$
$\frac{\text { characterization from 4.2 K to } 77 \mathrm{~K}}{\text { Y Jin, Q Dong, Y X Liang et al. }}$
- Power-scalable and high-speed orbital
$\frac{\text { anqular momentum modulator }}{\text { Jean-François Bisson, Katsuhiko }}$
Miyamoto and Takashige Omatsu
- A 3D dynamic model to assess the
$\frac{\text { impacts of low-mode asymmetry. }}{\text { aneurysms and mix-induced radiative loss }}$
$\frac{\text { on capsule performance across inertial }}{\text { confinement fusion platforms }}$
P.T. Springer, O.A. Hurricane, J.H.
Hammer et al.

The Electrochemical Society

243rd Meeting with SOFC-XVIII

Boston, MA • May 28 - June 2, 2023

Accelerate scientific discovery!
Learn More \& Register

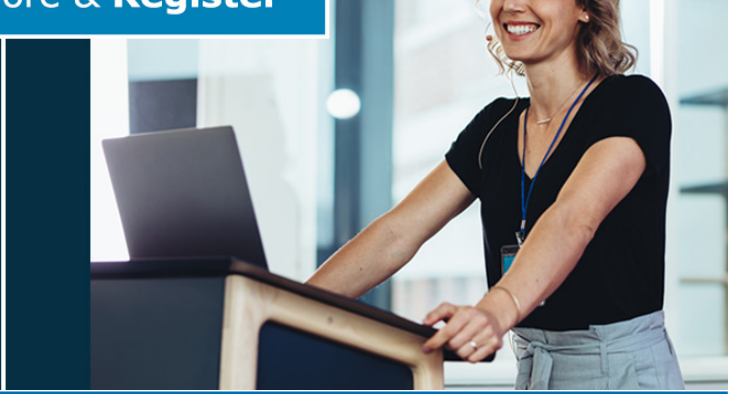


S03.09

Review of ocean temperature, salinity and oxygen changes in the Pacific and subtropical southern hemisphere

Lynne D Talley

Scripps Institution of Oceanography, UCSD, La Jolla, CA, USA

Temperature, salinity and oxygen changes over the past several decades in the Pacific and subtropical southern hemisphere are reviewed, along with their relation to changes in atmospheric forcing. The topic is reviewed based on inputs to the Intergovernmental Panel on Climate Change's Fourth Assessment Report, conclusions from that report, and results that have been obtained by numerous scientists since 2005 based on repeat hydrography, Argo observations and satellite observations. From 1955 to 2003, the oceans were warming, with $2 / 3$ of the heating in the upper $700 \mathrm{~m}$. The warming was not uniform; the subpolar North Atlantic and North Pacific and tropical Pacific warm pool were cooling, but not enough to offset the global warming trend.

Attribution of the upper ocean warming signal to climate change has been accomplished through combination of observed temperature change and climate models. Equatorial Pacific changes include strong signals in the shallow pycnocline that reflect ENSO variability, and which may be only tenuously related to climate change.

Salinity is changing regionally, with higher latitudes and the Pacific freshening, while lower latitudes and the Atlantic and Indian are becoming saltier, roughly consistent with a stronger atmospheric hydrological cycle, which is consistent with a warmer atmosphere and hence climate change. Oxygen had been decreasing in the pycnocline in subpolar regions, particularly in the North Pacific, consistent with decreased ventilation at the base of the climatological pyncocline, and likely shift of ventilation to warmer, lower density waters. However, increases in oxygen in the southern hemisphere subtropical pycnocline and concomitant changes in temperature and salinity reflect increased wind forced circulation within those regions. 